\title{
La Muerte en la Poesía de César Vallejo
}

César Vallejo sintió con obsesiva constancia la presencia de la muerte. Nació con el presagio de su temprana desapatición: "Me moriré en París con aguacero / un dia del cual tengo ya el recuerdo"; escribió el 2 de noviembre de I937: "Piedra negra sobre una piedra blanca"

En Los herdildos negros César Valiejo menciona la muerte. Suge. rida o expresada, ella será su "leit-motiv" para siempre. En las primeras composiciones predomina la descripción, y aun en ésta, se asocian la atmósfera y los colores. En "Deshora" leemos: "Pues la vida en la perenne tarde, / nació muy poco; pero mucho muere!" (O.C., p. 4I).

"Rosa blanca": romántico título de una composición de técnica moderna y original, es un poema en el que lo exclusivamente anecdótico, - lo descriptivo. deja lugar al lastimero canto "Y maya en mi Pacífico / un náufrago ataúd". (O. C., p. 58).

Si recordamos los accidentes biográficos de César Abraham Vallejo, rastrearemos en sus propios versos hasta qué punto la angustia de la muerte lo acompaña desde sus cantos premonitorios. Los colores domi. nantes en "Aldeana", por ejemplo, evocan el suelo natal: Santiago de Chuco: escenarios cargados de agonías milenarias, el "Yánguido yaravi", en la "vetusta aldea" "la triste voz del indio" semeja "un viejo aquilón de camposanto". El poeta, finalmente, confiesa con dramatismo concentrado: "suspiro una congoja, / al ver que la penumbra gualda y roja / llora un trágico azul će idilios muertos". ("Nostalgias Imperiales", O. C., pp. 53-54).

Observemos la identidad de estas palabras finales con el título de la

1 César Vallejo, Obras completas (Buenos Aires. Editorial Lozada, 1949), p. 191. En adelante citaremos, en el texto, por esta edición, que indicaremos con $O$. C. y la página respectiva. 
composición que analizaremos más adelante, llamada precisamente "Idilio muerto".

La muerte cobra relieves particulares en la poesía de Vallejo. Su ser contingente padece íntimamente su radical soledad. Las muertes particulares, individualizadas, recorren las páginas de su producción. En "Los pasos lejanos" (O. C., p. 76) la soledad del hogar lleno de rezos, con el hijo ausente, anuncia la lejanía ineludible. Doña María de los Santos Mendoza ha muerto (agosto de I9r8). La madre fallecida, "muerta inmortal", acude varias veces en los versos del hijo.

Los familiares desfilan con sus muertes, y cada uno se vuelve omnipresente. En "Hojas de ébano" ( $O$. C., pp. 46-47) se alude a una joven "trémula y triste" que "murió en la aldea". Se supone que trata sobre la pequeña hermana María "envueltita en su rebozo", la misma que aparece en los Poemas bumanos:

Murió en mi revólver mi Madre, en mi puño mi hermana y mi hermano en mi víscera sangrienta, los tres ligados por un género triste de tristeza, en el mes de agosto de años sucesivos ("La violencia de las horas", O. C., p. 242).

Una noche del mes de agosto de I9:5 desaparece el hermano Miguel, para quien escribió uno de sus más conocidos poemas: "A mi hermano Miguel", cuyo texto completo transcribimos a continuación:

"Hermano, hoy estoy en el poyo de la casa, / donde nos haces una falta sin fondo! / Me acuerdo que jugábamos esta hora, y que mamá / nos acariciaba: Pero hijos... / Ahora yo me escondo, / como antes, todas estas oraciones / vespertinas, y espero que tú no des conmigo. / por lia sala, el zaguán, los corredores. / Después, te ocultas tú, y yo no doy contigo. / Me acuerdo que nos hacíamos llorar, / hermano, en aquel juego. / Miguel, tú te escondiste / una noche de agosto, al alborear; / pero, en vez de ocultarte riendo, estabas triste. / $\mathrm{Y}$ tu gemelo corazón de esas tardes / extintas se ha aburrido de no encontrarte. Y ya / cae sombra en el alma. // Oye hermano, no tardes / en salir. ¿Bueno? Puede inquietarse mamá".

Muy a menudo Vallejo evidenciaba su intima relación con los muertos. En este caso, por ejemplo, se superponen: el hermano muerto (hoy) con el hermano que juega al escondite (ayer). Este entrecruzamiento de pianos pone "como una duda sobre la realidad de la muerte"2

2. Cfr. André Coyné, César Vallejo y su obra poética (Lima: Letras Peruanas, Biblioteca de Escritores Peruanos dirigida por Jorge Pucinelli). 
Ls por eso que el poeta insiste con el verbo recordar y los adverbios de tiempo. I.a reiteración obra el efecto sicológico buscado: "boy estoy en el poyo de la casa" Y en seguida aclara: "Me acuerdo que jugábamos". Después, salta hacia el pasado con una palabra casi mágica: "ahora yo me escondo". Y aclara en el verso siguiente: "como antes". El tiempo continúa moviéndose sigilosamente: "Después te ocultas tú". No en vano, entre los juegos infantiles, Vallejo ha elegido la escondida. La muerte también oculta en su juego a Miguel: "Miguel, tú te escondiste / una noche de agosto" ("Nostalgias Imperiales", O. C., pp. 76-77)..$^{3}$

Los más íntimos desaparecen y en la hora de la comida la orfandad se siente más punzante. En este humilde acto el poeta revive el pasado y ofrenda su abandono: "He almorzaćo solo ahora, y no he tenido, / madre, ni súplica, ni sírvete, ni agua; ni padre... ("Trilce", poema XXVIII, O. C., p. I05).

En "La cena miserable", perteneciente a Los beraldos negros, su minúsculo yantar se convierte en letanía de irreparable miseria: "Y cuándo nos veremos con los demás, al borde / de una mañana eterna, desayunando todos! / Hasta cuándo este valle de lágrimas, adonde / yo nunca dije que me trajeran". El verso final acentúa el clamor ćesespe. rado: "hasta cuándo la cena durará!" (O.C., p. 64). El artista aguarda un desayuno luminoso y pleno; tan sólo le ha tocado una oscura cena. La reiteración interrogante y exclamativa de estos versos impone el ritmo dramático y creciente del poema.

César Vallejo, al llorar a los seres que le dieron la vida, a los hermanos de la sangre, va marcando su vivir-morir, concepto que no se limita al ámbito familiar; lo proyecta en su raza:

Hay ficus que meditan, melenudos trovadores incaicos en derrota.

El cholo Vallejo se refirió varias veces al indígena vencido. Su queja por la muerte del pasado ćebemos considerarla despacio. Para José Carlos Mariátegui la voz de Vallejo se confunde con la del indio; para otros críticos, en cambio, la suya es la expresión del mestizo con agudas protestas sentimentales, $y$ a veces, metafísicas. Coincidimos con el pensa-

3 Sobre el conflicto de la tempotalidad en Vallejo, véase: Xavier Abril, Vallejo, ensayo de aproximación crítica (Buenos Aires: Edición Front, 1958), pp. 56.57. 
miento de André Coyné y subrayamos la fina intuición vallejana manifestada a través de sus "Nostalgias Imperiales", donde expresa algo mucho más profundo y existencial, que un mero lamento por un pasado desaparecido. En esas "nostalgias" "los viejos curacas", "los muertos dominios", "el viejo coraquenque cesterrado", "el huaco gigante que vigila", "la abuela amargura", "las pallas aquenando hondos suspiros", "el indio triste", y "'a pastora de lana y llanque" vestida, marchan en agónica peregrinación obedeciendo a un fatum intransferible. La terminología empleada resulta significativa; los colores pálidos, opacos, las nieblas, las derrotas y los ocasos, junto con verbos de grave contenido marcan el conjunto desolador de un paisaje íntimo más opaco aún que el marco exterior. La libertad idiomática se acentúa en estos poemas con un doble matiz: el estético (lleno de equijibrio y belleza estilística) y el conceptual (densamente trágico).4

El "huaco gigante que vigila" se levanta, como si Vallejo no se resignara a la muerte total. Hay alguien que permanece en actitud espectante, aguardando el futuro (que no tiene por qué ser, necesariamente, ni un retorno histórico, ni un despertar del pasado, pero si, puede significar una vigilia más honda; es decir: una conciencia en vela meta. física).

Veamos ahora cómo siente Vallejo el amor frente a la muerte:

$Y$ los labios se encrespan para el beso, como algo lleno que desborda y muere.

Para él, el amor no sobrevive en el tiempo. El fracaso constante de la vida, en la quimérica posesión amorosa, marca la afirmación de la muerte. El cántico de amor que leemos en Los beraldos negros lleva por título, como decíamos antes "Idilio muerto". Comienza con una remembranza: "Qué estará haciendo esta hora mi andina y dulce Rita / de junco y capuli". El verso final lleva el vacio interior que la evocación reclama: "Y llorará en las tejas un pájaro salvaje". (O. C., p. 54).

En "El poeta a su amada" la muerte se mueve entre los amantes. El poeta revela su intimidad con ella. Pintura goyesca la de la siguiente escena: "En esta noche rara que tanto me has mirado / la Muerte ha

4 Sobre el problema del lenguaje en Vallejo Cfr.: César A. Angeles Caballero, Los peruanismos en César Vallejo (Lima. Editorial Universitaria, 1958). 
estado alegre y ha cantado en su hueso". Amada, moriremos los dos juntos; muy juntos; / se irá secando a pausas nuestra excelsa amargura; / y habrán tocado a sombra nuestros labios difuntos". (O. C., p. 37).

La relatividad de lo humano debemos consumarla hasta que la muerte nos salve del girar incesante. Como en la danza medieval, et. amor y la muerte dan vuelta inexorablemente.

Después, la tumba-mujer termina por atraer al hombre. Parece como si el poeta gozara con su fatal ćestino. Con cierto deleite romántico, ese tono se detiene al decir: "La tumba es todavía / un sexo de mujer que atrae al hombre!" ("Desnudo en barro", $O$. C., p. 6r).

En "Traspié entre dos estrellas" la pareja se eleva a la unidad perfecta, "sin dos". El planteo filosófico se insinúa; lo que antes era tumba-hombre $=$ mujer-hambre, ahora es unidad..$^{5}$

En la prosa incluida en los Poemas bumanos bajo el título de "El momento más grave de la vida" compara la casa con la tumba: "... la casa se nutre de la vida del hombre, mientras que la tumba se nutre de la muerte del hombre". (O.C., p. 233).

Parece un poco exagerado hablar de nutrición, tratándose de 1 a tumba. Vallejo en muchas composiciones humaniza a la muerte, de tal modo, que le atribuye cualidades, necesidades o caracteres ajenos a ella. Sicológicamente es importante observar la constante en la obra poética del peruano. La cena, el almuerzo, el desayuno son meros símbolos de su apetencia afectiva y filosófica que le hace decir:

En suma, no poseo para expresar mi vida sino mi muerte.

En "Espergesia", quien intuye la agonía de su temprana miseria, confiesa: "Hay un vacío / en $\mathrm{mi}$ aire metafísico / que nadie ha de palpar" (O.C., p. 79).

La aparente oposición vida-muerte cobra en Valjejo, armónicamente, una re'ación de causa-efecto existencial. El poema LXXV de Trilce (O. C., p. 144) declara: "Y sin embargo, los muertos no son, no

5 Scbre el tema Cfr.: Juan Larrea, César Vallejo en la sruz de su razón (Universidad Nacional de Córdoba, Centro de Estudiantes de Filosofía y Letras, 1957), p. 24. 
pueden ser cadáveres de una vida que todavia no han vivido. Ellos murieron siempre de vida". La aclaración de estas palabras, aparentemente herméticas, la hallamos unas líneas más adelante, cuando dice: "Os digo, pues, que la vida está en el espejo, y que vosotros sois el original, la muerte".

La vida, entonces, no es más que apariencia, reflejo de una imagen real que existe fuera de ella misma. El poeta identifica a la vida (imagen de la muerte) con el espejo. La esencia filosófica del tema, nos lleva a detener nuestra atención en los verbos empleados: ellos constituyen un punto de partida en e? buceo metafísico. Los verbos ser y estar aparecen en el "Sermón sobre la muerte": "pero yo sufro, como te digo / dulcemente, recordando / lo que hubimos sufrido ambos a la muerte de ambos, en la apertura de la doble tumba, / de esta otra tumba en tu ser, / y de ésta de caoba con tu estar". (O. C., p. I78).

La temporalidad del estar la subrayó al traernos la imagen de "caoba", como símbolo de cacucidad, de finitud.

Las preguntas límites que se formula el poeta, en una suerte de tétrico contrapunto, las resume en pareados que titula sugestivamente: "Yuntas" (O. C., p. 203): "Completamente. Además; vida! / Completamente. Además; muerte! / Completamente. Además; Dios! Completamente. Además; nadie! / Completamente. Además; nunca! / Completamente. Además; siempre!"

César Vallejo se mueve entre las antípodas. La economía expresiva lograda, acentúa aquí, la fuerza angustiosa que domina su existencia. Su enfermedad, el desamparo, sus dolores físicos y morales, le hicieron vislumbrar su muerte anticipadamente. Dice en "París, octubre 1936" (O. C., p. I74): "De todo esto yo soy el único que parte. / Y me alejo de todo, porque todo / se queda para hacer la coartada".

El escritor argentino Raúl González Tunón rememora su primer, encuentro en París, a través de una página conmovedora: "Encontramos a un Vallejo - dice-muy suave y cordial, pero amargado, tristón, alicaído. Escribía poco o nada, en medio de privaciones, de una silenciosa pobreza de la cual parece ahora avergonzarse su viuda, y la cual para nosotros enaltece y agranda el recuerdo de César". ${ }^{6}$

Las circunstancias lo asedian; pero no son ellas las causas funcamentales de su mal. Lo dice expresamente: "Si no me llamase César Vallejo, también sufriría este mismo dolor. Si no fuese artista, también

6 Reportaje realizado a $R$. González Tuñón por la revista Eco contemporáneo, Buenos Aires, $\mathrm{N}^{\circ}$ 5, p. 55. 
lo sufriria. Si no fuese hombre, ni ser viviente siquiera, también lo sufriría. Si no fuese católico, ateo, ni mahometano, también lo sufriría. Hoy sufro desde más abajo. Hoy sufro solamente" ("Voy a hablar de la esperanza", O. C., p. 237).

Hay en la obra vallejana muchas contradicciones, como consecuencia de la sensibilidad del artista. El no pretende exponer con rigor cien. tífico esas verdades de validez universal que lo atormentan. Enrique Anderson Imbert se refiere a esto, cuando señala: "Los poemas de Trilce son irracionales, ininteligibles; pero sólo conmueven aquellos en que Vallejo ha elaboraco sentimientos comunes a todos los hombres".?

Su realidad personal se hermana con la realidad político-social del momento. "España, aparta de mí este cáliz" constituye el testimonio vivo de quien padece el conflicto hondamente. Su visión va más allá de la tesis revolucionaria. Para él la revolución era di acto necesario que había de resolver inmediatamente los problemas sociales, económicos, pero sin poder impedir que vuelvan a surgir las demás inquietuces del hombre, especialmente la angustia frente al tiempo y a la muerte.

Este "clásico moderno", como lo llamó muy acertadamente Xavier Abril, después de llorar a los muertos de toda España, declara: "Sólo la muerte morirä".

La muerte significa lo negativo, el mal, aquello que no debe sobrevivir.

Con la "Imagen española de la Muerte" nos entrega, en castizo lenguaje, su adiós definitivo: "La muerte es un ser sido a la fuerza, / cuyo principio y fin llevo grabados / a la cabeza de mis ilusiones" (O. C., p. 264).

$\mathrm{Y}$ ahora, es Vallejo quien busca a la Muerte: “ ¿Llamadla! ¡Daos prisa! Va buscándome, $/$ con su coñac, su pómulo moral, $/$ sus pasos de acordeón, su palabrota". (O. C., p. 264).

El 15 de abril de 1938 la Muerte recogía el reclamo.

NORMA PÉREZ MARTÍN

Buenos Aires

$7 \mathrm{Cfr}$. Enrique Anderson Imbert, Historia de la Literatura Hispanoamericana (México: Fondo de Cultura Económica, 1961), t. II, p. 58. 
